\title{
Interferometric Calibration with Natural Distributed Targets
}

\author{
Dall, Jørgen; Christensen, Erik Lintz
}

Published in:

Proceedings of the IEEE 2002 International Geoscience and Remote Sensing Symposium

Link to article, DOI:

10.1109/IGARSS.2002.1024977

Publication date:

2002

Document Version

Publisher's PDF, also known as Version of record

Link back to DTU Orbit

Citation $(A P A)$ :

Dall, J., \& Christensen, E. L. (2002). Interferometric Calibration with Natural Distributed Targets. In Proceedings of the IEEE 2002 International Geoscience and Remote Sensing Symposium (Vol. 1). IEEE. https://doi.org/10.1109/IGARSS.2002.1024977

\section{General rights}

Copyright and moral rights for the publications made accessible in the public portal are retained by the authors and/or other copyright owners and it is a condition of accessing publications that users recognise and abide by the legal requirements associated with these rights.

- Users may download and print one copy of any publication from the public portal for the purpose of private study or research.

- You may not further distribute the material or use it for any profit-making activity or commercial gain

- You may freely distribute the URL identifying the publication in the public portal 


\title{
Interferometric Calibration with Natural Distributed Targets
}

\author{
J. Dall and E.L. Christensen \\ Electromagnetic Systems, Ørsted $\bullet D T U$, Technical University of Denmark \\ Ørsteds Plads 348, DK-2800 Kongens Lyngby, Denmark \\ Tel: +45 4525 3800, Fax: +45 4593 1634, E-mail: jd@oersted.dtu.dk
}

\begin{abstract}
Cross-calibration is a fully automated algorithm for calibration of interferometric synthetic aperture radar (IFSAR) data. It has been developed for single-pass interferometry, but the principles may be applicable to multi-pass interferometry, too. The algorithm is based on natural distributed targets and it excels by neither requiring surveyed ground control points nor dedicated calibration scenes. However, the parameters to be calibrated must be stable during mapping. The algorithm has been applied to data from the Danish airborne SAR, EMISAR, and the performance has been assessed. The algorithm appears to be fairly robust with respect to the terrain type. However, the result of the calibration may deteriorate if the terrain elevation, as measured with the SAR, changes systematically with the incidence angle or the aspect angle.
\end{abstract}

\section{INTRODUCTION}

Systematic errors in digital elevation models (DEMs) generated from interferometric synthetic aperture radar (IFSAR) data may be caused by inaccurate navigation data, inaccurate system parameters, system imperfections etc. Often natural or man-made ground control points (GCPs) are used for calibration, but proper GCPs may not be available, and deploying GCPs and/or surveying them is troublesome. Calibration scenes with known elevation, e.g. a sea surface, have been used successfully [1], [2], but such scenes do not always exist near the target scene and this techniques also requires that the parameters to be calibrated remain unchanged while both the calibration scene and the target scene are mapped.

An IFSAR calibration technique called cross-calibration requires neither GCPs nor dedicated calibration scenes. The principles and the mathematics have been presented in a previous paper [3], and so have the convergence properties [4]. The basic algorithm provides a relative calibration, but it can be extended to offer a (coarse) absolute height calibration [4].

This paper focuses on the performance of the crosscalibration, after a brief algorithm review in Section II. Section III presents a calibration example and examines the robustness of the algorithm, e.g. the impact of the scene topography. In Section IV the impact of surface penetration and azimuthal symmetry is discussed.

\section{AlgORITHM REVIEW}

The cross-calibration algorithm estimates calibration parameters for each of two DEMs acquired from crossing tracks. The mapping geometry in Fig. 1 is typical, but it should be noted that the DEMs do not have to cross at right angle. If multiple parallel slave DEMs are to be calibrated as in Fig. 1 the reliability of the calibration can be evaluated by comparing the master calibration parameters obtained with the different slaves. Alternatively, once the first crosscalibration has been completed the master calibration can be fixed and the calibration of the remaining slaves can be based on a scene with known elevation, viz. the master.

The calibration parameters are corrections to physical SAR parameters and navigation parameters, e.g. phase bias and roll bias. Alternatively, an equivalent phase error can be estimated. This is the phase error that causes the same height error as the physical parameter errors actually cause in all. Basically, the equivalent phase error is a function of the interferometric phase only, and hence the calibration can be accomplished by simply adjusting this interferometric phase.

The cross-calibration algorithm is based on the difference between the two crossing DEMs and consequently it is (to the first order) unaffected by a constant height added to both DEMs. This means that the basic cross-calibration algorithm does not support absolute height calibration. If an accurate absolute calibration is required a potential constant height offset must be eliminated with other means, e.g. with a GCP. Alternatively, a cause absolute height can be estimated from the relative misregistration that is caused by a potential constant height error.

The fact that miscalibration and misregistration are associated is also what makes cross-calibration an iterative algorithm. Especially in case of steep terrain slopes the misregistration translates into additional height differences, which, although they tend to be stochastic, lead to a suboptimal calibration. Fortunately the algorithm converges quickly. Two

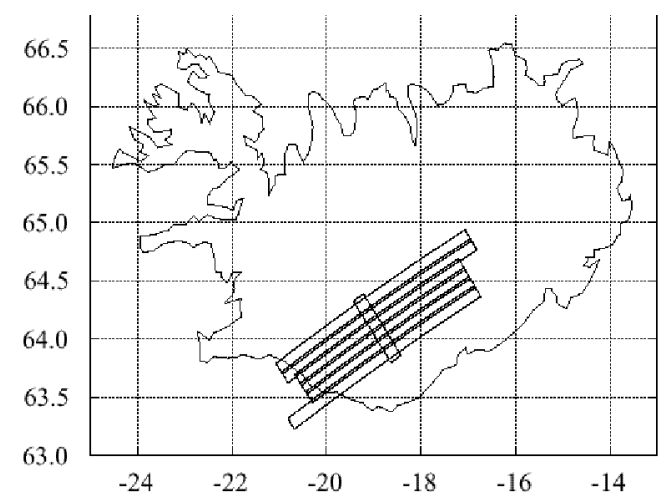

Fig. 1. Typical mapping geometry where one master DEM calibrates several crossing slave DEMs. 


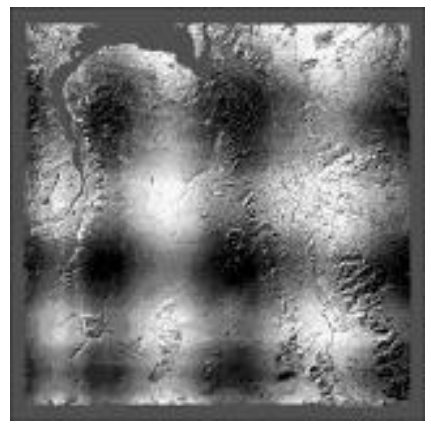

(a)

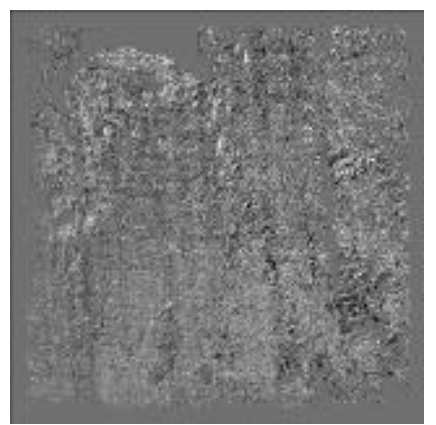

(b)
Fig. 2. Differental DEMs. (a) Before calibration: $17 \mathrm{~m}$ peak-peak height. (b) After calibration: $0.9 \mathrm{~m}$ height noise in both DEMs.

iterations are usual sufficient even for a mountainous area [4].

Each strip can be calibrated in its entirety if the navigation system and the SAR system are stable while mapping. The stability is not required to span both of the crossing DEMs as separate sets of calibration parameters are estimated for the master and slave DEMs [3], [4].

\section{ROBUSTNESS}

Fig. 2 shows the difference between a master DEM and a slave DEM before and after calibration. The date are acquired with the Danish airborne SAR, EMISAR [5] over an undulating agricultural area. The miscalibration in Fig. 2a is primarily due to multi-path propagation caused by an onaircraft reflection [1].

Fig. 3 illustrates the accuracy of the technique. The monotonous dashed curve shows the phase error equivalent to an elevation error of $1 \mathrm{~m}$. Near range is to the right. The dashdot curve is the equivalent phase error as estimated from a nearby sea surface. The differences between this phase error and two equivalent phase errors estimated with crosscalibration are shown with the two solid curves. Both curves are associated with the same master strip but with two adjacent slaves. One of the two cross-calibrations is that shown in

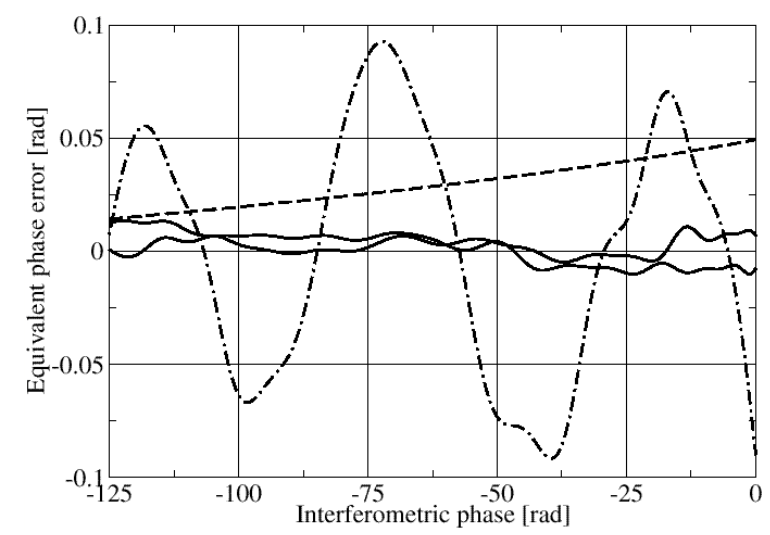

Fig. 3. Calibration based on a sea surface and the deviation from two cross-calibrations performed with adjacent slaves. Phase error equivalent to a $1 \mathrm{~m}$ elevation error.

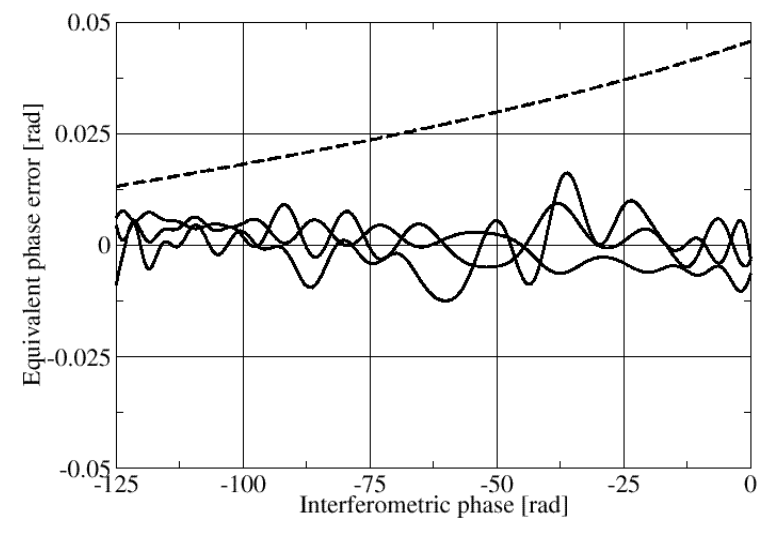

Fig. 4. Master phase errors found by cross-calibration with three adjacent slaves. The deviation from their mean is shown.

Fig. 2. From Fig. 3 two conclusions can be drawn. Firstly, the two solid curves do not differ much, although the corresponding cross-calibrations are based on different slaves / intersection areas. Secondly, the two solid curves are close to zero, implying that the cross-calibrations give almost the same result as the calibration with the sea surface.

Fig. 4 further illustrates the insensitivity to the scene topography, this time with a mountainous area in Iceland. Three estimates of a master phase error are obtained by crosscalibration with three adjacent slaves. The figure shows the difference to the mean of the three phase errors. It is seen that the three results do not differ much. Again, the dashed curve is the equivalent phase error corresponding to $1 \mathrm{~m}$ of height error.

The importance of system stability is illustrated in Fig. 5 . The slave DEM (left-right strip) was given a motion compensation error, and hence a height error of about $2 \mathrm{~m}$. Fig. 5 shows that the cross-calibration translates this azimuth varying slave error into a range varying calibration error in the master (up-down strip). Note that while the motion compensation error in Fig 5a is tilted a bit due to squint, the calibration error in Fig. 5b is not. The algorithm assumes the calibration error to be independent of azimuth. The small undulations of the pattern in Fig. 5b are due to the fact that the

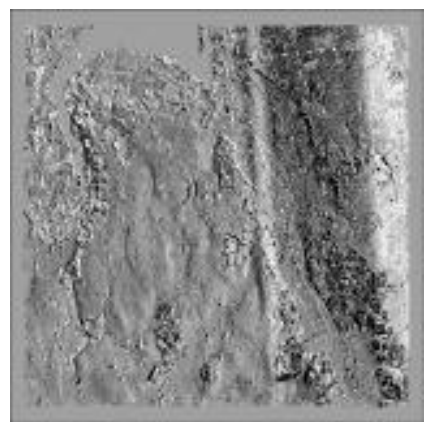

(a)

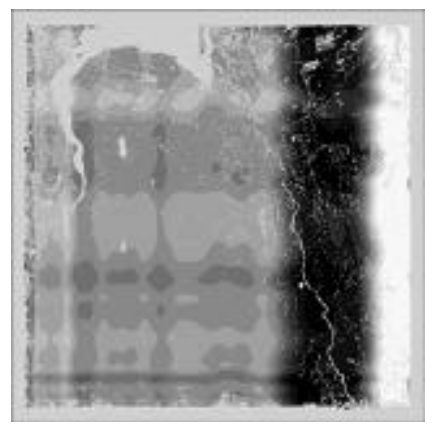

(b)
Fig. 5. Slave instability in azimuth causes master miscalibration. (a) Measured master/slave height difference. (b) 2D height error corresponding to the estimated phase errors. 


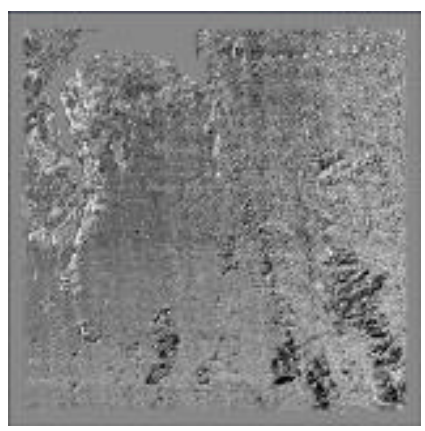

(a)

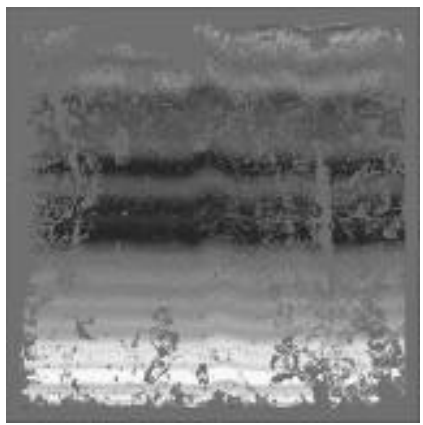

(b)
Fig. 6. Forest penetration may cause minor calibration errors.

ground range corresponding to a fixed interferometric phase varies with terrain height and aircraft roll.

\section{PENETRATION}

For the cross-calibration algorithm to work properly the SAR must see a scene with azimuthal symmetry, i.e. the same effective terrain height must be seen from each of the two crossing tracks.

In the differential DEM in Fig. 6a (slave minus master) the forest appears light to the left (steep incidence of master) and dark at the bottom (steep incidence of the slave) because the vertical penetration depth increases with decreasing incidence angle. For part of the forest, the penetration depth in Fig. 6a is up to $8 \mathrm{~m}$ larger at near range than at far range. This is measured in the upper left corner and in the lower right corner. Since the cross-calibration algorithm attempts to match the master/slave elevations in all parts of the intersection area, the penetration makes the calibration lift the non-forested areas in the near range. This lift increases with the penetration depth and with the relative forest cover.

By using the interferometric correlation forest areas with large penetration can be masked out, as penetration is associated with volume scattering and hence decorrelation. Fig. $6 \mathrm{~b}$ shows a differential DEM, viz. the slave DEM calibrated with Fig. 6a minus a slave DEM cross-calibrated after application of a correlation mask, i.e. the 'true' DEM. The lift in the light area at the bottom of Fig. $6 \mathrm{~b}$ is about $20 \mathrm{~cm}$.

As demonstrated, the penetration effect can be eliminated if the scene is only partly covered by forest. The effect cannot be eliminated if a penetration depth changing with the incidence angle characterizes the entire scene. Such a situation could be expected when mapping ice sheets, for instance.

The Geikie ice cap in East Greenland has been mapped by EMISAR and prior to the flight radar reflectors had been deployed and measured very accurately with phase-differential GPS. The interferometry data were processed and calibrated with the cross-calibration algorithm. In the DEM, the reflector heights were compared with the elevation of the ice surrounding the reflectors, and it was observed that the difference depends on the incidence angle. The vertical penetration depth at the near range reflectors exceeds that at the far range reflectors by $0.8 \mathrm{~m} \mathrm{[6].} \mathrm{On} \mathrm{this} \mathrm{background} \mathrm{it} \mathrm{was} \mathrm{expected}$ that the cross-calibration algorithm would lift the near range reflectors as explained above. Indeed, the difference between the reflector heights measured with SAR and with GPS is on the average $1.0 \mathrm{~m}$ larger in near range than in far range [6]. However, this result should be interpreted with care as the standard deviation is about the same as the average of the four measurements. In summary, in combination with ice penetration the cross-calibration algorithm may cause a minor range dependent miscalibration.

\section{SUMmary}

The performance of the cross-calibration algorithm has been assessed using EMISAR data covering three different scene types: an undulating agricultural area in Denmark, a mountainous area in Iceland, and an ice cap in Greenland. The algorithm estimates calibration parameters for each of two interferometric data sets acquired from crossing tracks. In general the algorithm performs excellently and the calibration result is very similar to that obtained when using a sea surface for calibration.

The algorithm appears to be quite insensitive to the terrain type as the variation of the calibration result from one intersection area to another is about the same for the agricultural area as for the mountainous area. The parameters to be calibrated must remain stable during mapping. Otherwise the results cannot be extended from the intersection area to the entire strip. Also, it has been demonstrated that the algorithm translates azimuth instability of one data set into a calibration error of the crossing one. Finally, a slight miscalibration may result if the elevation, as measured with the SAR, changes systematically with the incidence angle or the aspect angle.

By nature, cross-calibration is iterative, but even for a mountainous area it is usually sufficient with two iterations each taking a few minutes of computer time.

\section{REFERENCES}

[1] S.N. Madsen, N. Skou, K. Woelders, and J. Granholm, "EMISAR Single pass Topographic SAR interferometer modes", International Geoscience and Remote Sensing Symposium, IGARSS'96, pp. 674-676, Lincoln, Nebraska, USA, May, 1996.

[2] J. Dall, J. Grinder-Pedersen, S.N. Madsen, "Calibration of a High Resolution Airborne 3-D SAR", Proceedings of the International Geoscience and Remote Sensing Symposium, IGARSS'97, pp. 1018-1021, Singapore, August, 1997.

[3] J. Dall, S.N. Madsen, K. Keller, R. Forsberg, "Using Airborne SAR Interferometry to Measure the Elevation of a Greenland Ice Cap", Proceedings of the IEEE 2000 International Geoscience and Remote Sensing Symposium, IGARSS2000, pp. 1125-1127, Honolulu, July 2000.

[4] J. Dall, "Calibration of Airborne single-pass interferometry data", Proceedings of the EUSAR 2002 conference, in print, Cologne, June 2002.

[5] S.N. Madsen, N. Skou, J. Granholm, K. Woelders, and E.L. Christensen, "A System for Airborne SAR Interferometry", $A E \ddot{U}$, Vol. 50, 1996, No. 2, pp 106-111, and Eusar'96, pp 171-176, Königswinter, Germany, March 1996.

[6] J. Dall, S.N. Madsen, K. Keller, R. Forsberg, "Topography and Penetration of the Greenland Ice Sheet Measured with Airborne SAR Interferometry”, Geophysical Research Letters, Vol. 28, No 9, pp. 1703-1706, 2001 . 